\title{
Numerical Investigation of Velocity Flow Field inside an Impeller Air Model of a Centrifugal Pump with Vaned Diffuser Interactions and Comparison with PIV Measurements
}

\author{
Abdelmadjid Atif, ${ }^{1}$ Saad Benmansour, ${ }^{1}$ and Gerard Bois ${ }^{2}$ \\ ${ }^{1}$ Laboratory of Advanced Mechanics, FGMGP/USTHB, BP32 El Alia, Alger 16111, Algeria \\ ${ }^{2}$ Laboratory of Mechanics of Lille, ENSAM-Lille, 8 Building Louis XIV, 59046 Lille, France
}

Correspondence should be addressed to Gerard Bois, gerard.bois@ensam.eu

Received 7 July 2010; Accepted 30 October 2010

Academic Editor: E. Y. K. Ng

Copyright ( $\odot 2010$ Abdelmadjid Atif et al. This is an open access article distributed under the Creative Commons Attribution License, which permits unrestricted use, distribution, and reproduction in any medium, provided the original work is properly cited.

\begin{abstract}
The paper refers to the analysis of interactions between the impeller and the vaned diffuser on the air model of a radial flow pump. The study deals with a numerical simulation of the flow for a full $360^{\circ}$ entire impeller and diffuser. The task is carried out close to design operating conditions and for one particular position of the impeller blade with respect to diffuser frame. Among all the results, it has been decided to mainly focus on the flow pattern at the exit part inside the impeller coming from the diffuser vanes interactions. The results are compared to the available PIV measurements.
\end{abstract}

\section{Introduction}

The flow in a radial pump is highly three dimensional, spatially nonuniform, and intrinsically unsteady. Departure from axisymmetric or periodic assumptions was strongly highlighted by previous works $[1,2]$. The diffuser vanes are found to play a major role in establishing the circumferential flow fields near the exit of the impeller [3]. This rotorstator interaction results in both upstream and downstream flow variations in time and space, which generates noise, vibrations, and unfavorable characteristics to pump performance even at design conditions. The so-called jet and wake structure that have been highlighted by several authors such as Johnston and Dean [4] impose nonuniform inlet conditions to vaned diffuser and strong interactions between rotor and stator blades. Knowledge improvement of unsteady effects and rotor-stator interactions in radial flow pumps has already been a favorite research theme for a large number of researchers. A great number of rotor-stator interactions analyses based on experimental and modeling activities have been realized $[5,6]$, but still further investigations are needed so that pump designs could benefit from controlling the undesirable aspects in order to construct them in a more reliable and quiet operation.

With the evolution of LDV and PIV techniques, it has been possible to measure velocity fields within the impeller and the diffuser of radial flow pumps [7, 8]. They have been performed to provide reliable data for discussion and validation.

With nowadays computer performances and dedicated codes, numerical simulations of flow inside the impeller and diffuser are proposed with reasonable precision, providing a close look at the flow development through the pump. To be able to capture the unsteady effects by numerical simulation, it should be undertaken a full $360^{\circ}$ study for both impeller and diffuser in transient mode. However, this technique is high cost in computer resources and time. An alternative approach is the so-called frozen rotor made at fixed relative positions. It is less requiring in memory and allows for a quicker mean to analyze the flow inside the pump $[9,10]$.

\section{Numerical Procedure}

2.1. Pump Geometry. The pump is modeled as a set of three components: an entry duct, impeller, and vaned diffuser 


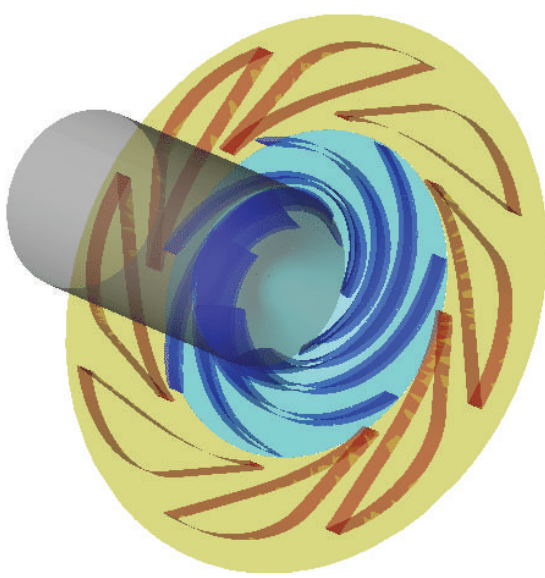

Figure 1: Pump geometry.

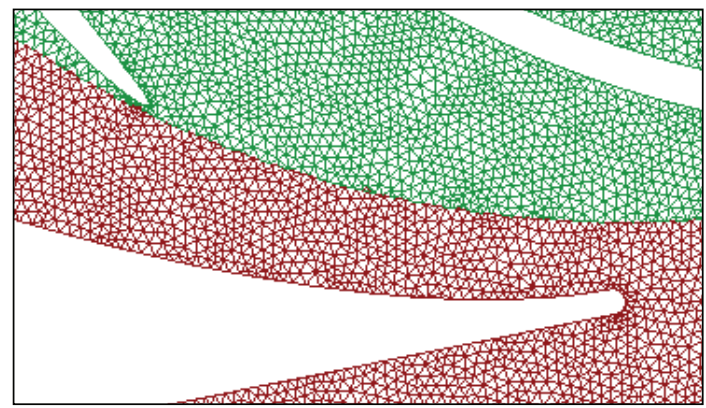

FIgURe 2: Mesh details.

as shown in Figure 1. Impeller rotates clockwise. The entry duct is chosen long enough to assume uniform upstream inlet flow conditions. No flow leakage occurring in the gaps between rotating and stationary parts was accounted for in the numerical study. However, concerning the experimental setup, a $0.3 \mathrm{~mm}$ gap does exist at impeller shroud tip inlet section and at impeller outlet both at hub and shroud. In this respect, the impeller inlet mass flow rate has been evaluated taking into account this leakage flow.

2.2. Test Conditions. The numerical simulation of the complete $360^{\circ}$ impeller and diffuser is carried out for a particular impeller blade position relative to the vaned diffuser ones, in order to characterize part of the unsteady effects that appear within the impeller when it rotates in front of the stationary vaned diffuser. The choice of this particular blade position has been recognized from previous work to be the one for which the diffuser vanes may greatly affect impeller flow field.

The pump is tested at the same conditions as the experimental procedure, at a flow rate close to impeller design $\left(Q^{*}=0.934\right)$. It should be noted that the diffuser was designed to be fitted at $80 \%$ of the impeller design flow rate. This was intended to improve performance at low flow rates.

The main features of the components and specifications of operating conditions are summarized in Table 1.

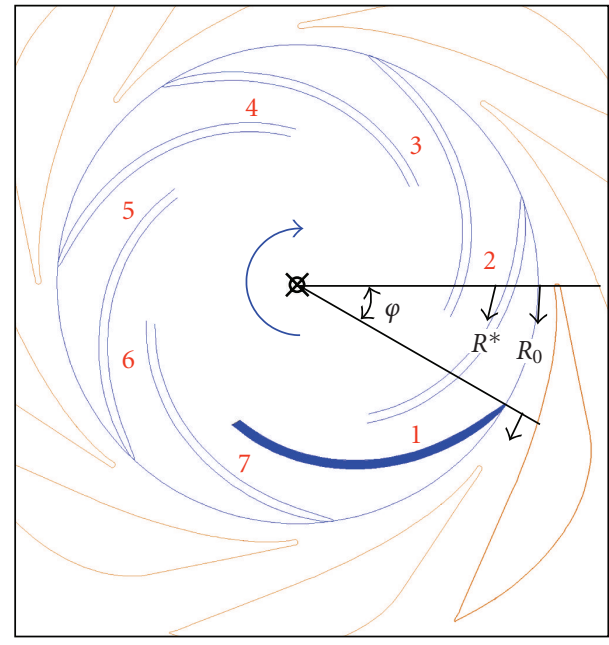

Figure 3: Passage numbering.

TABLE 1: Specifications of the pump.

\begin{tabular}{|c|c|}
\hline \multicolumn{2}{|c|}{ Test conditions } \\
\hline Speed of rotation & $1710 \mathrm{rpm}$ \\
\hline Normalized flow rate & $Q^{*}=Q / Q n=0.934$ \\
\hline Fluid & Air at $25^{\circ} \mathrm{C}$ \\
\hline \multicolumn{2}{|c|}{ Entry duct } \\
\hline Diameter & $0.1411 \mathrm{~m}$ \\
\hline Length & $0.5129 \mathrm{~m}$ \\
\hline \multicolumn{2}{|c|}{ Impeller } \\
\hline Inlet radius & $0.1411 \mathrm{~m}$ \\
\hline Outlet radius & $R_{o}=0.2566 \mathrm{~m}$ \\
\hline Number of blades & 7 \\
\hline Outlet height & $B_{o}=0.0385 \mathrm{~m}$ \\
\hline Outlet blade angle & $22.5^{\circ}$ \\
\hline Main blade position & $\varphi=30.03^{\circ}$ \\
\hline Design flow rate & $Q_{n}=0.337 \mathrm{~m}^{3} / \mathrm{s}$ \\
\hline \multicolumn{2}{|c|}{ Diffuser } \\
\hline Inlet radius & $0.2736 \mathrm{~m}$ \\
\hline Outlet radius & $0.3978 \mathrm{~m}$ \\
\hline Number of vanes & 8 \\
\hline Height & $0.040 \mathrm{~m}$ \\
\hline Design flow rate & $0.8 Q_{n}$ \\
\hline
\end{tabular}

2.3. Mesh Structure. The pump is completely meshed with unstructured tetras (see Figure 2 for some details). Tetras are more flexible elements to model complex passage geometries, but the outcome is a larger problem dimension. Mesh refinements are placed at particular locations like blade edges, walls, and interfaces.

Mesh characteristics for each of the three components are listed in Table 2.

2.4. Computations. Computations are performed using CFX 12.1 CFD code. Three-dimensional, steady incompressible 


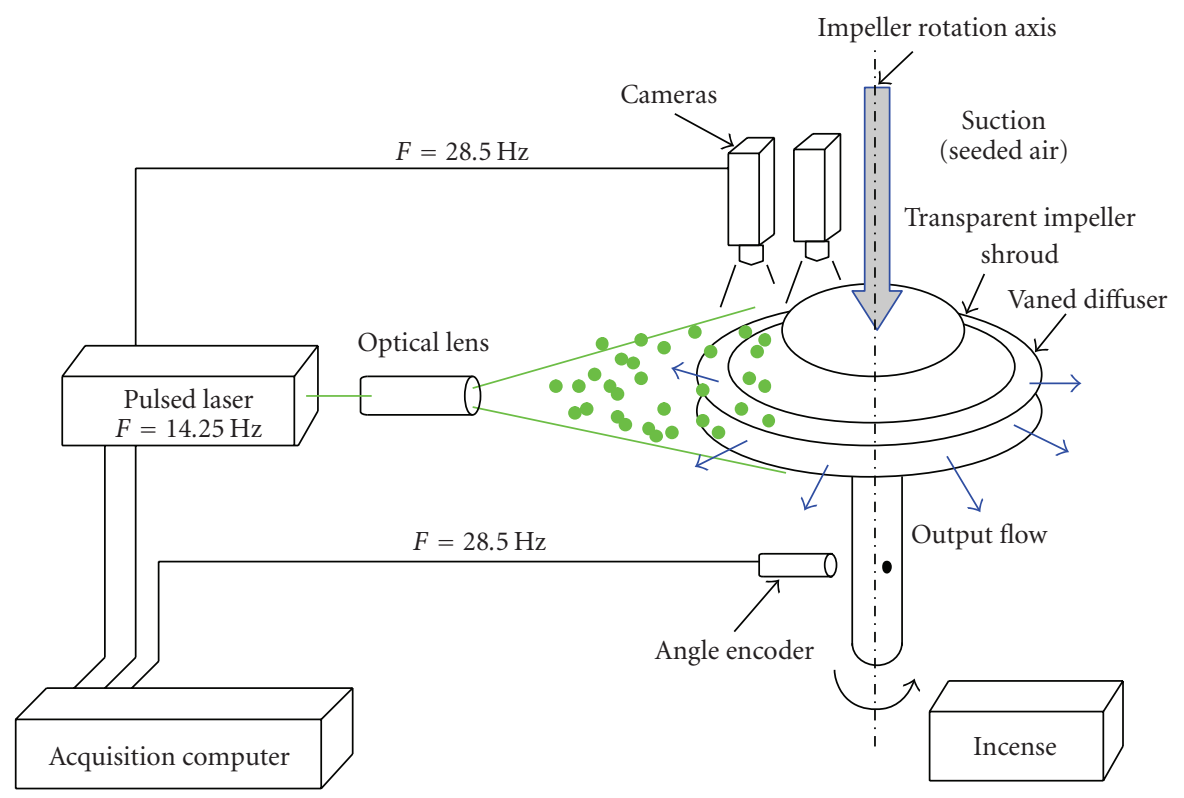

Figure 4: Test setup.

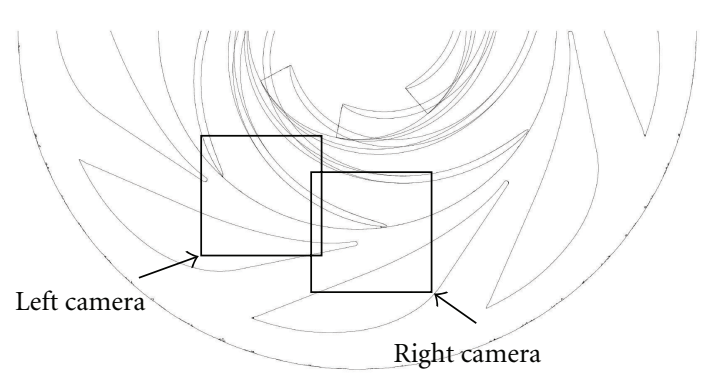

Figure 5: Location of PIV cameras.

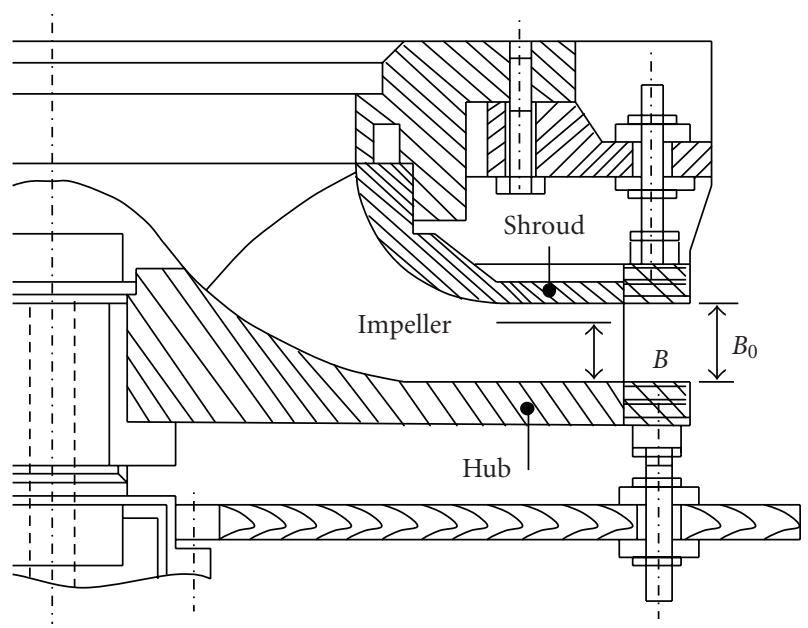

Figure 6: Outlet height measurement planes.

Reynolds-averaged Navier-Stokes are solved. The turbulence is simulated with $\mathrm{k}-\omega$-based SST model recommended for turbomachinery flows, in combination with specific

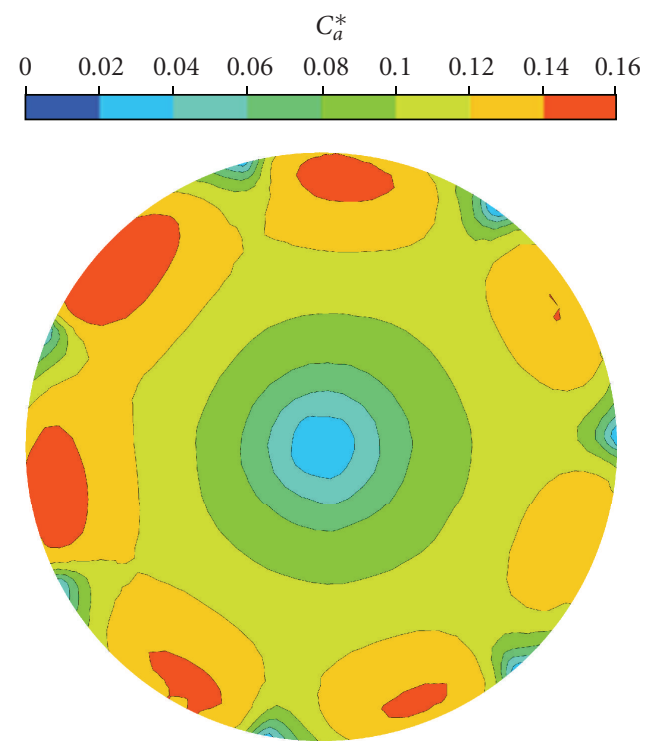

FIGURE 7: Impeller inlet axial velocity distribution.

TABLE 2: Mesh information.

\begin{tabular}{lcc}
\hline Component & Tetra elements & Nodes \\
\hline Entry duct & 1420202 & 267845 \\
Impeller & 4291744 & 851701 \\
Diffuser & 4684173 & 930695 \\
\hline Total & 10396119 & 2050241 \\
\hline
\end{tabular}

near-wall treatment, that is, it automatically switches from a low-Re formulation to wall functions based on the grid spacing provided by the user. The main 


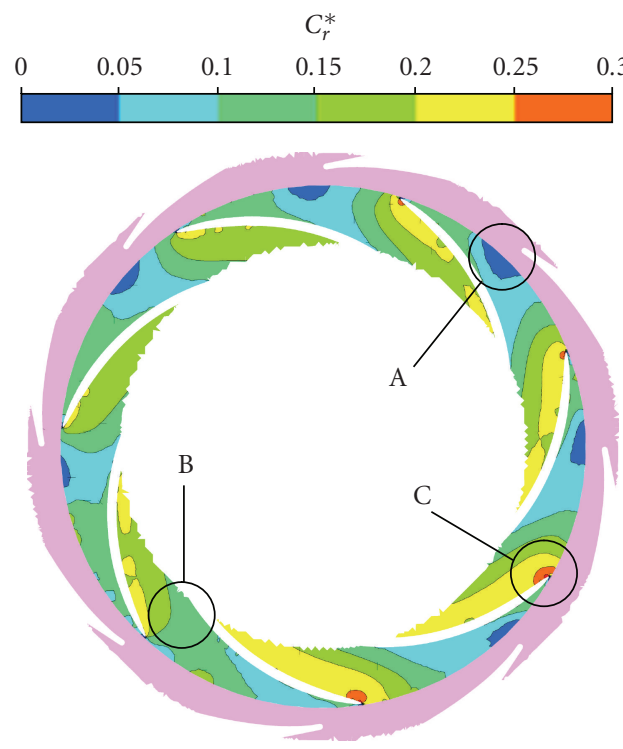

(a)
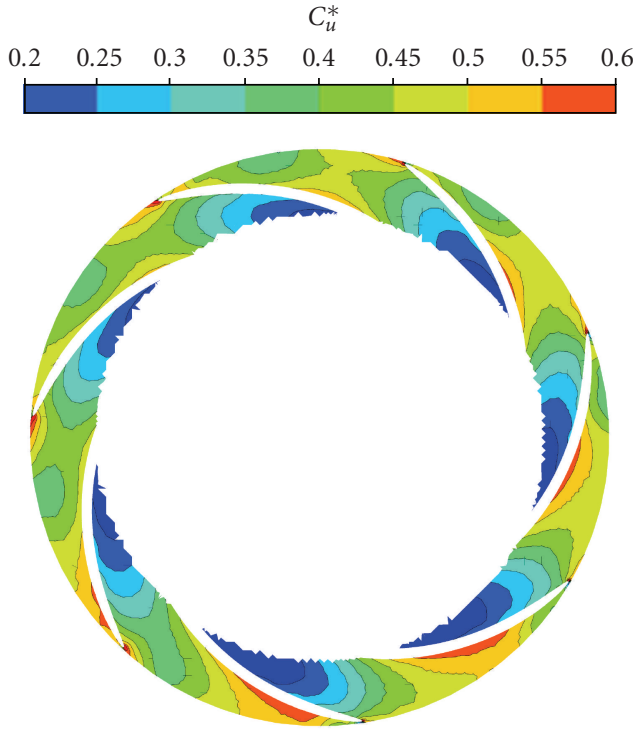

(b)

FIGURE 8: Impeller midheight outlet radial and tangential velocity distributions.

features for numerical simulation are summarized in Table 3 .

2.5. PostProcess. For a more precise analysis of the influence of the diffuser vanes on the flow within the impeller, the passages are numbered in a counter-clockwise way starting from the main blade as shown in Figure 3. $\theta$, the circumferential location in degrees, is positive clockwise. $\theta$ equal to 0 , is located at the impeller main blade trailing edge. Simulation data are extracted on three blade-to-blade constant radius lines as also shown in Figure 3 (see Table 4 for definition). This allows illustrating velocity fields at the impeller outlet and comparing with experimental results.

All velocities are normalized with respect to the impeller outlet circumferential velocity $U_{0}$.

\section{Experimental Procedure}

Tests have been performed in air with the so-called SHF impeller, on a test rig specially adapted to study impellerdiffuser interactions (see Figure 4). The impeller flow can be analyzed both with vaneless and vaned diffusers. No volute is placed downstream of the diffuser to avoid further interactions. Therefore, the flow at the outlet of diffuser discharges directly into surrounding atmosphere.

For the vaned diffuser test, PIV fields have been measured simultaneously with two cameras in the impeller outlet part and within the diffuser (see Figure 5), only at midheight between hub and shroud (see Figure 6). The experimental procedure allows for determination of mean absolutes velocities in two exposure frames, for up to 9 different impeller angular positions relative to diffuser vanes. Further details on PIV techniques used, experimental setup and result interpretations are described by Wuibaut et al. [11].
TABle 3: Computation details.
Inlet section of entry duct

Outlet section of diffuser

Walls

Fluid

Turbulence model

Maximum number of iterations

Convergence criteria
Specified mass flow rate

Constant zero pressure [Referred to atmospheric pressure]

Smooth and no slip

Constant property air at $25^{\circ} \mathrm{C}$

$$
\text { k- } \omega \text {-based SST }
$$

100

Mass residues less than

$5 \times 10^{-5}$ Momentum residues less than $5 \times 10^{-4}$
TAble 4: Normalized Radii definition.

\begin{tabular}{cccc}
\hline$R^{*}=R / R_{0}$ & $R_{1}^{*}$ & $R_{2}^{*}$ & $R_{3}^{*}$ \\
& 0.855 & 0.919 & 0.974 \\
\hline
\end{tabular}

Tests were also carried out for the vaneless diffuser at exactly the impeller design flow rate [12]. The vaneless diffuser was short with an outlet radius of $287.5 \mathrm{~mm}$ (see Figure 6). These results are assumed to be the general periodic flow pattern inside the impeller passage without vaned diffuser interaction and are used for qualitative comparison with the present study since they are not exactly acquired at the same locations and flow rate.

PIV technique is subjected to optical aberrations due to laser reflections on blade walls, shadows, and laser sheets superposition. These effects appear as local discontinuities in the velocity field as can be seen later in Figure 14. The results have been selected to take off false values corresponding to undesirable optical effects by data reduction procedure as explained by Wuibaut et al. [13]. 


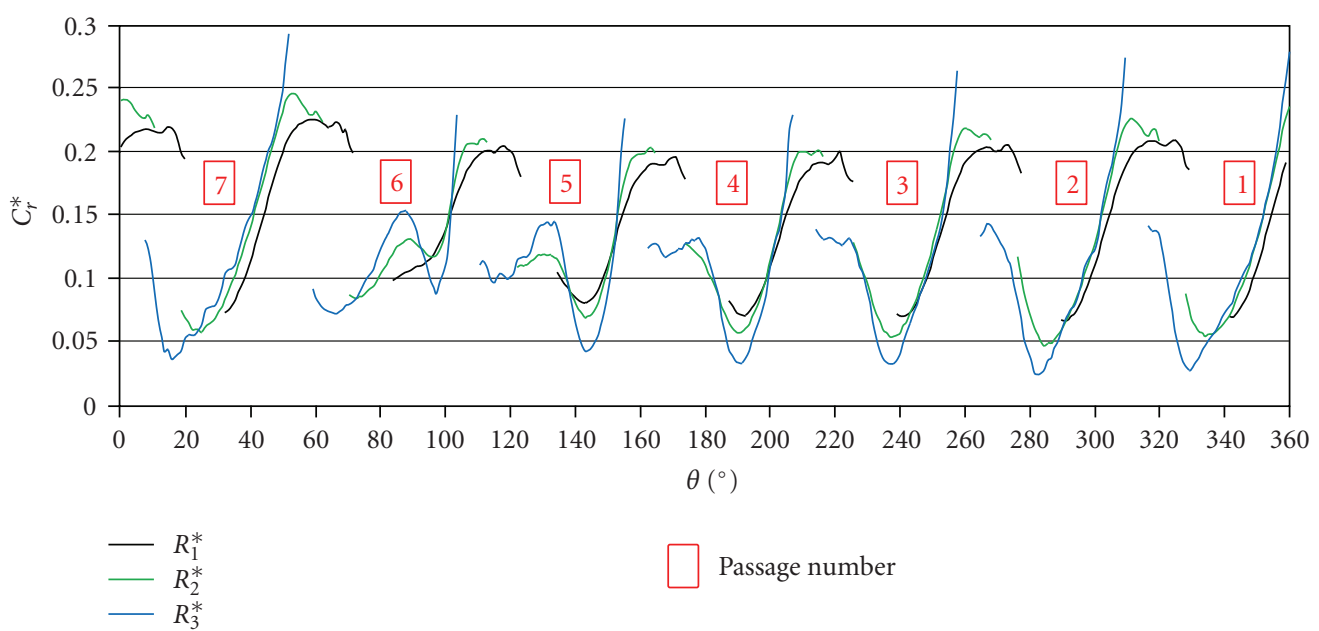

(a)

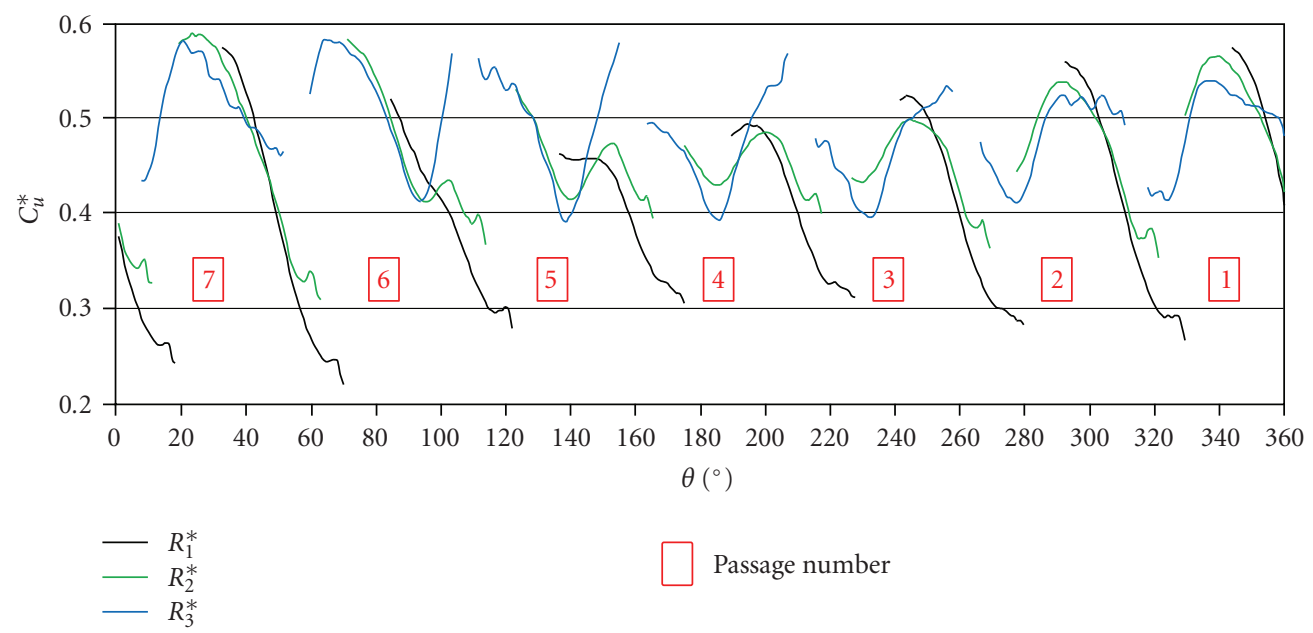

(b)

FIGURE 9: Circumferential distribution of radial and tangential velocities at impeller midheight outlet.

\section{Results and Discussion}

4.1. Axial Velocity at Impeller Inlet. Figure 7 shows the distribution of normalized axial velocity $C_{a}^{*}$ at the inlet section of the impeller in order to show that vaned diffuser effects may occur far upstream in the pump.

\subsection{Radial and Tangential Velocity at Impeller Midheight} Outlet. Figure 8 shows the distribution of the normalized radial $C_{r}^{*}$ and tangential $C_{u}^{*}$ velocities at impeller midheight outlet (normalized height $B^{*}=0.5$ ). The pink color is to illustrate the diffuser vane locations.

The figure clearly shows the effect of diffuser vanes on the flow structure inside the impeller blade passages. The flow is not periodic as expected with a vaneless diffuser. It means that no impeller passage is completely unaffected by the presence of diffuser vanes.

For $C_{r}^{*}$, depending on the impeller blade position with respect to the diffuser vane, we can notice 3 particular zones in the passages named A, B, and C.
A: zone of low radial velocity, present in almost all passages, whose size and circumferential location depend on the blade position. It is more important when the vane is facing the flow around the midpassage. The diffuser vanes are in the trajectory of the flow leaving the rotor pressure side, therefore making this side of the impeller channel more sensitive to the proximity of the diffuser [11].

B: in this particular passage, the zone of low radial velocity tends to disappear completely when the diffuser vanes blockage effects coincide with impeller blade ones.

C: located at some impeller blades suction side. It is a zone of high radial velocity due to aerodynamics effects from diffuser vanes.

For $C_{u}^{*}$, higher tangential velocities occur along the pressure side compared to low values of radial velocities. 


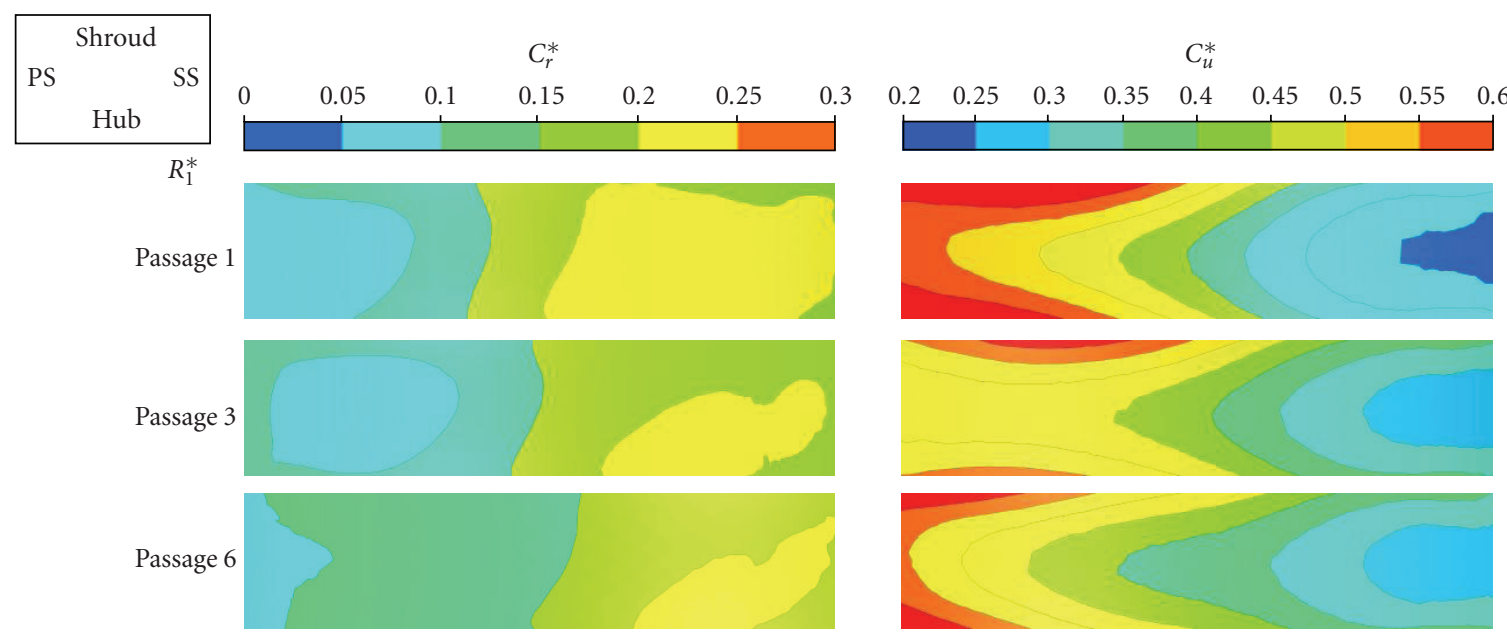

(a)
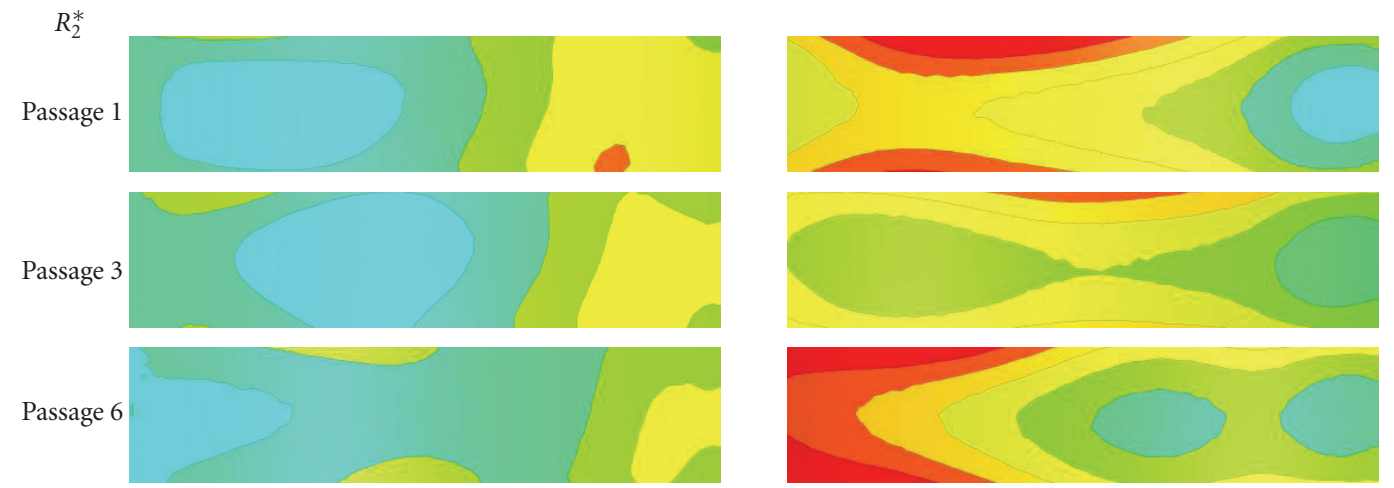

(b)
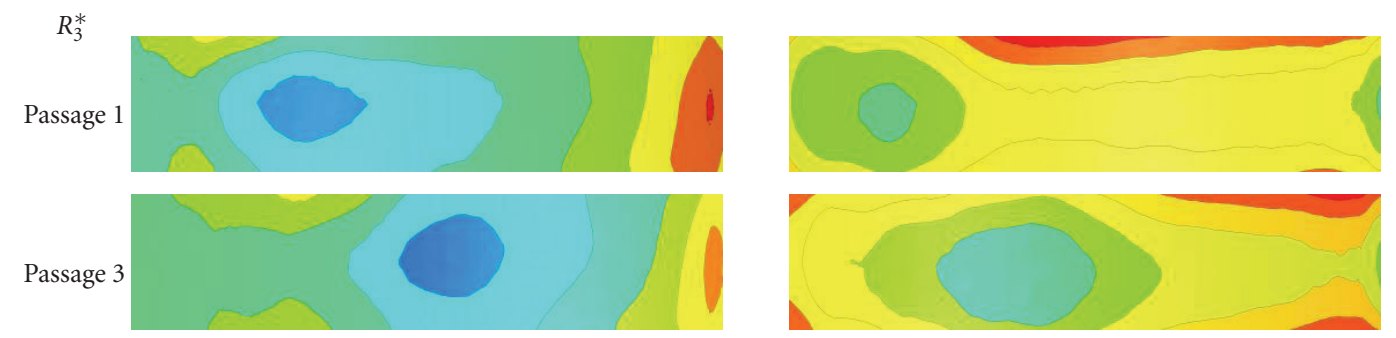

Passage 6
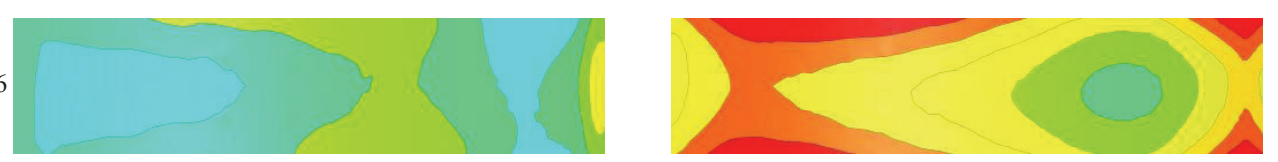

(c)

FIgURE 10: Blade-to-blade and hub-to-shroud distribution of radial and tangential velocities for selected passages.

4.3. Radial and Tangential Velocity Circumferential Distribution at Impeller Midheight Outlet. Figure 9 shows the circumferential distributions of the normalized radial and tangential velocities at impeller midheight outlet, for the three selected radii. Impeller rotates from left to right.

It is evident that appreciable variations are observed from one passage to another. This suggests strong interaction effects from diffuser vanes, and that the periodicity of the flow among all impeller passages can no longer be assumed as for vaneless diffuser case.
The radial velocity is not so much affected by the vaned diffuser for line of low radial location $R_{1}^{*}$. For $R_{2}^{*}$ and $R_{3}^{*}$ locations, the upstream effect of the diffuser is evident. Passages 1,2, and 7 globally differ from the other impeller blade passages.

Concerning the tangential velocity, there is always a strong upstream effect of the vaned diffuser even at low radial location $R_{1}^{*}$.

4.4. Overall View of Radial and Tangential Velocities for Selected Passages. Figure 10 shows the blade-to-blade and 


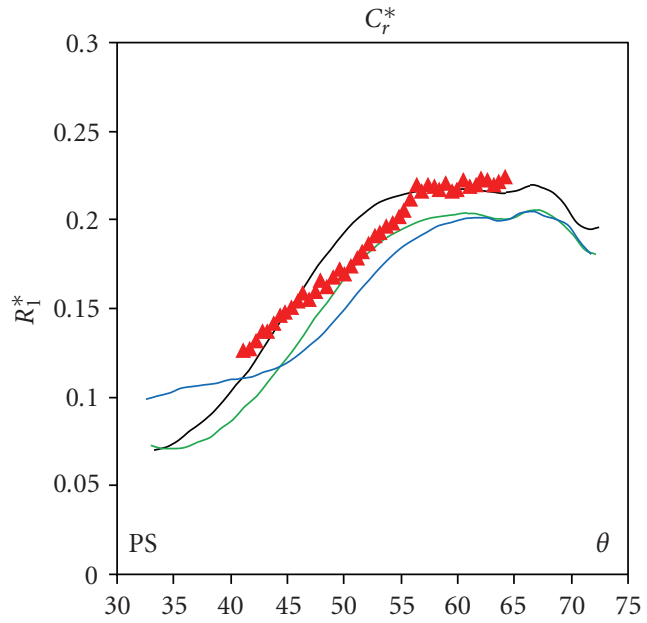

(a)

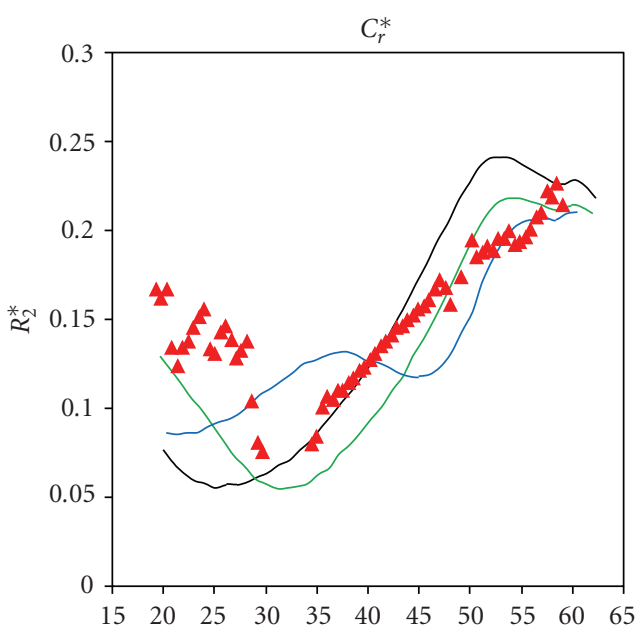

(c)

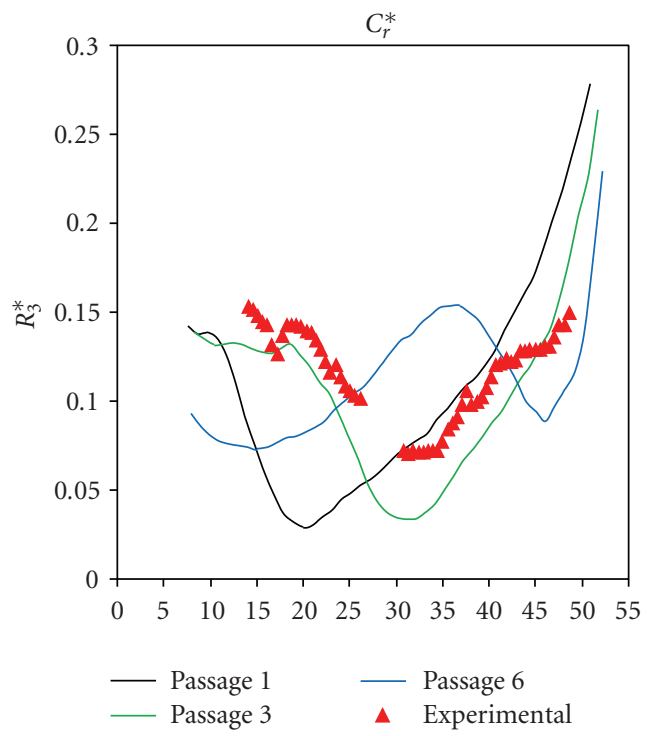

(e)

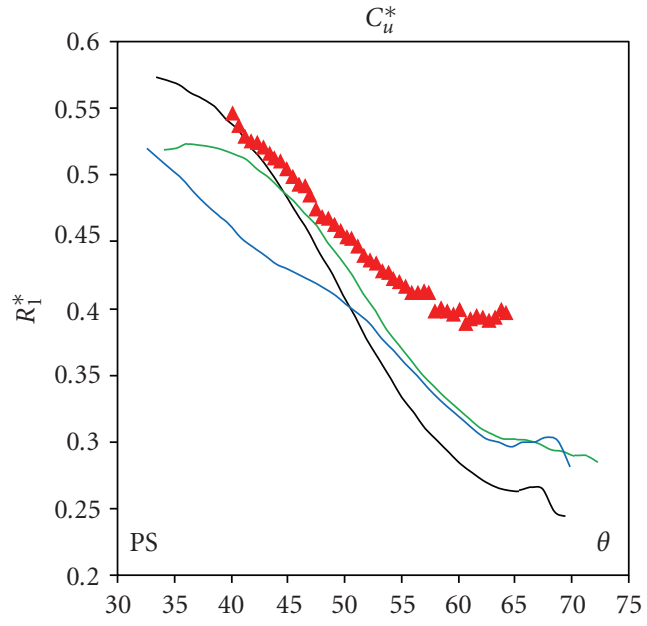

(b)

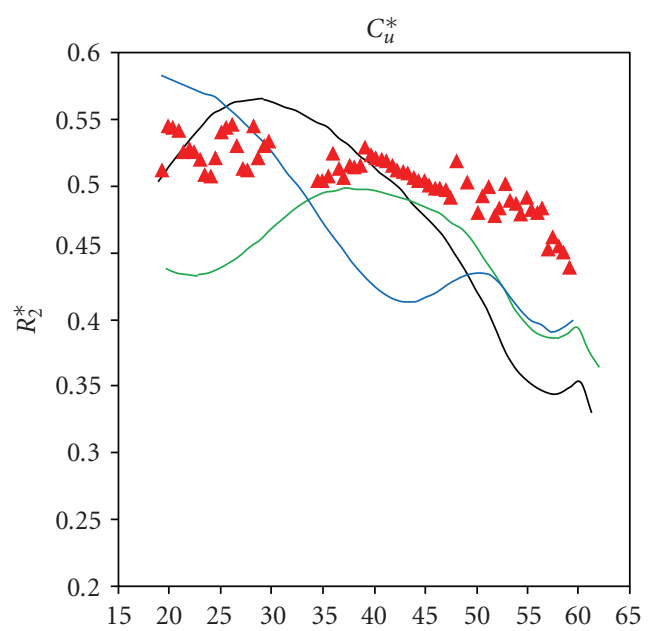

(d)

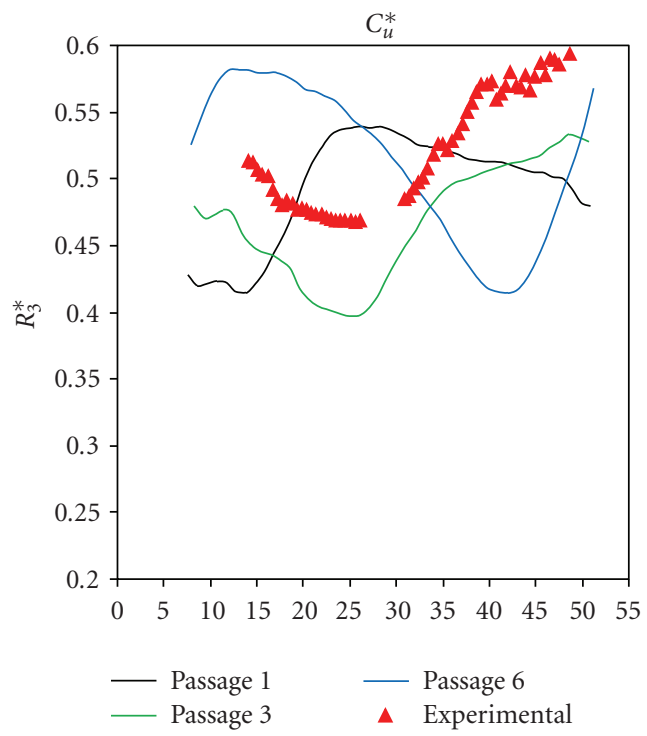

(f)

Figure 11: Blade-to-blade distribution of radial and tangential velocities for selected passages. 

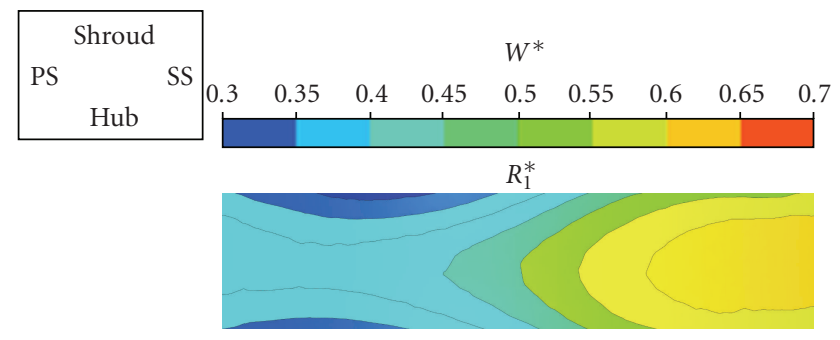

$R_{2}^{*}$

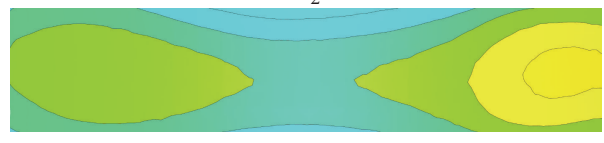

$R_{3}^{*}$

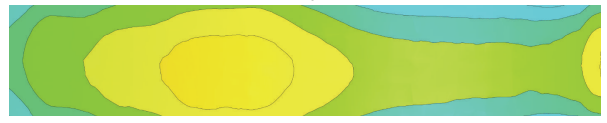

FIgURE 12: Blade-to-blade and hub-to- shroud distribution of relative velocity for passage 3 .

the hub-to-shroud distributions of the normalized radial and tangential velocities for three selected passages of the impeller (1,3, and 6). For all figures, impeller rotates from left to right. It defines the pressure side (PS) at left and the suction side (SS) at right. Hub is located down in the passage and shroud up.

From a general point of view, it is clear that noticeable variations are observed from one passage to another, with passage 6 different, specially at $R_{3}^{*}$, due to the fact that it is less affected by diffuser vanes. Gradients of velocity are observed between the hub to shroud as well as in the circumferential direction although some symmetry patterns are found around the midheight circumferential line for $C_{r}^{*}$ and $C_{u}^{*}$, but not in the same form.

For $C_{r}^{*}$, it is almost symmetrical around the midheight circumferential line, but the gradients are low in the hub-to-hroud direction, which makes radial velocity almost constant in this direction. The zones of low radial velocity are mainly located at exit around the midheight line.

For $C_{u}^{*}$, is quite symmetrical around the midheight circumferential line but the gradients are high in the hub to shroud direction, which makes tangential velocity extremely varying in this direction.

\subsection{Blade-to-Blade Distribution of Radial and Tangential Velocity at Impeller Midheight Outlet. Figure 11 presents the blade-to-blade plots of the normalized radial and tangential velocities at midheight plane for the three selected passages of the impeller. Here $\theta$ equal to 0 is located at the impeller blade trailing edge pressure side of the corresponding passage. \\ Remarkable variations are observed from one passage to another, which means that no impeller passage is completely unaffected by the presence of diffuser vanes.}

This strong interaction effects exist not only at $R_{3}^{*}$ but also at $R_{2}^{*}$ and $R_{1}^{*}$, but with decreasing effects farther away from vane leading edges, as discussed in the following.

At $R_{1}^{*}$, all velocity profiles show similar gradient with close values. This is the less affected by diffuser vanes.

At $R_{2}^{*}$, all velocity profiles show similar gradient, but with the presence of local minima or maxima, that clearly depends on the blade position.

At $R_{3}^{*}$, the same observations are found as for $R_{2}^{*}$, but with much greater influence of diffuser vanes. The 3 passages show quite different patterns, with local minima or maxima. The location of these extrema is closely linked to the blade position.

4.6. Comparison with Experiments. Comparisons with experimental data are presented to see how well the present study can simulate the unsteady interaction between impeller and vaned diffuser.

The experimental data are only acquired for passage 1, midheight plane. They are extracted on the same selected blade-to-blade constant radius lines. Figure 11 shows the experimental data along with the numerical curves for the radial and the tangential velocities.

The numerical velocity profiles are in relatively good agreement with the experimental results, since the slopes and the magnitudes inside the impeller are well predicted for both velocities. However, measurements tend to give higher velocities, about $10 \%$ more than computed one. One reason is that midheight plane for experimental measurements can be mislocated towards hub or shroud, which gives higher velocity values due to the high velocity gradients around the midheight line, especially for $C_{u}^{*}$, as has been observed in Figure 10.

Experimental results show both higher velocities when approaching the blade walls, especially the suction side part. The agreement is better at midcircumferential location in the impeller. One may suggest some uncertainties in data processing regarding flow angle differences between air flow and seeding particles used to get PIV data. This particular point needs further investigations with other flow rates and other PIV measurements.

The more the location in the impeller goes close to the impeller outlet plane, the more the experimental results diverge from the numerical ones. This discrepancy may also be strongly influenced by the leakage occurring in the clearance gap between impeller and diffuser. One may also suggest that the flow in this interaction region is too complicated to model correctly or to measure experimentally.

Experimental data show behaviors rather closer to numerical results for passage 3 , which is not the passage investigated in the experimental procedure since PIV information is acquired with passage 1 synchronism. This suggests that maybe a kind of a time delay exists for the PIV to effectively acquire the passage 1 data. This "time delay" is estimated to be the time for the impeller to rotate between these two passages. Complete unsteady calculation will give more details upon this point. 


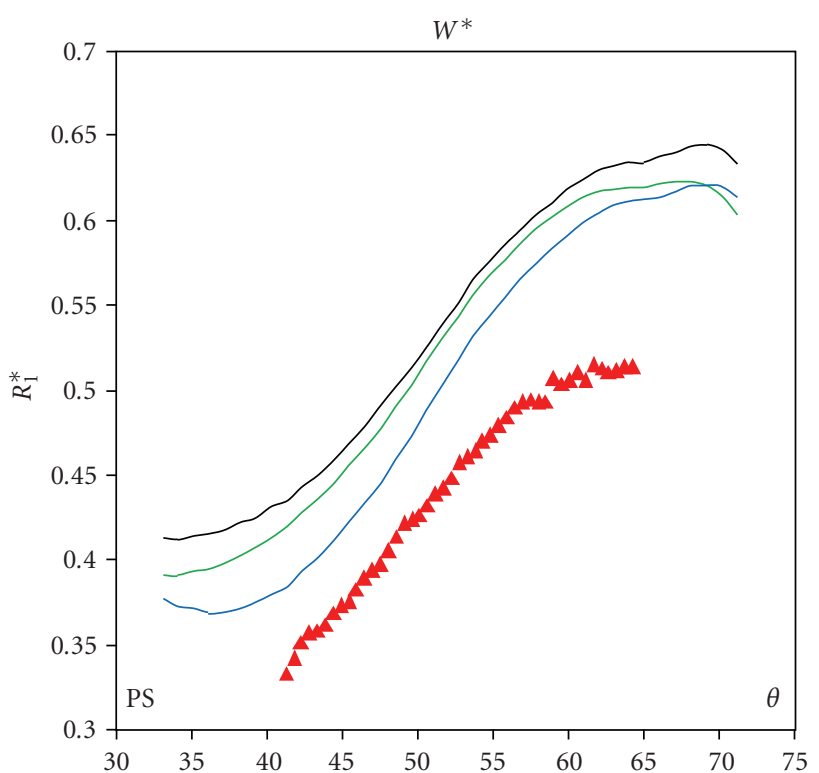

(a)

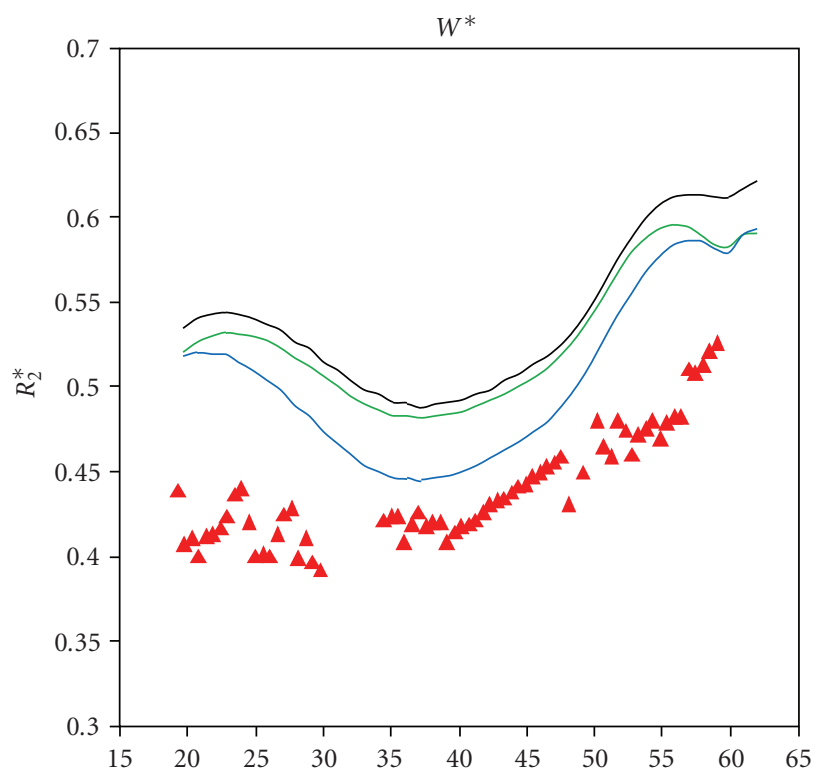

(b)

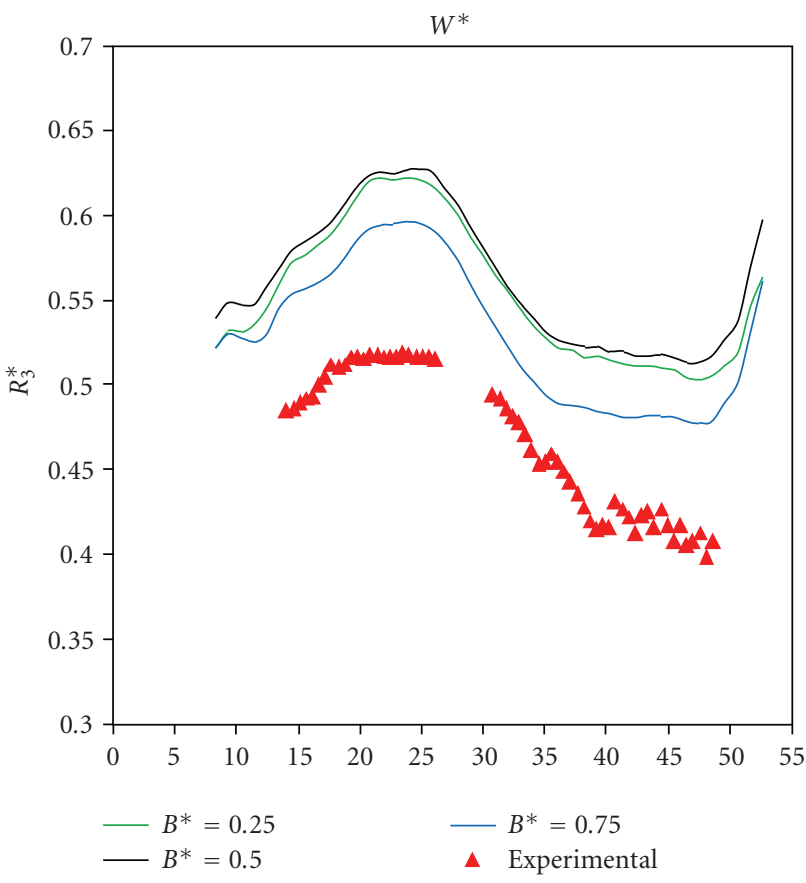

(c)

FIGURE 13: Blade-to-blade relative velocity evolution for vaned diffuser.

Numerical-experimental discrepancies can also be explained by several other causes. First main cause is the fact that steady state assumption cannot take into account the unsteady effects due to impeller rotation. Other causes may concern numerical procedure, mesh refinement dependency, turbulence model, boundary conditions, and data processing. It must be pointed out that there are some shortcomings of using PIV; sources of errors are measurement uncertainties, optical problems, unsteady effects, and data processing.
4.7. Overall View of Relative Velocity at Impeller Outlet. Figure 12 shows the blade-to-blade and the hub-to-shroud distributions of the normalized relative velocity $W^{*}$ for passage 3 of the impeller. Nonuniformities are observed between the hub to shroud as well as in the circumferential direction, but it also shows a flow rather symmetrical around midheight circumferential line. Relative velocity is slightly lower near the shroud side than the hub one. These results are different from the case of the vaneless diffuser ones which highlighted a large zone of low relative velocity at the suction 


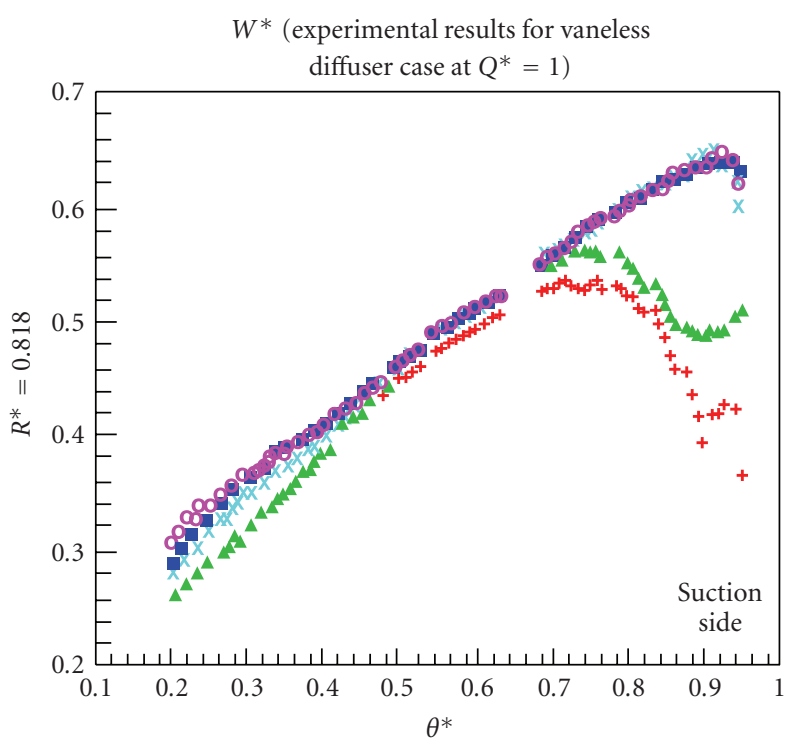

(a)

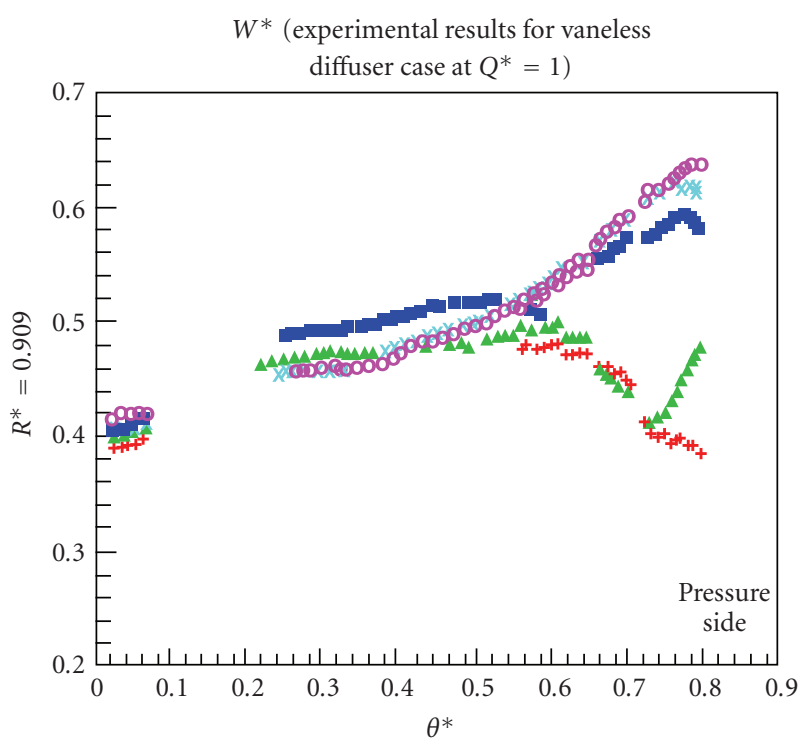

(b)

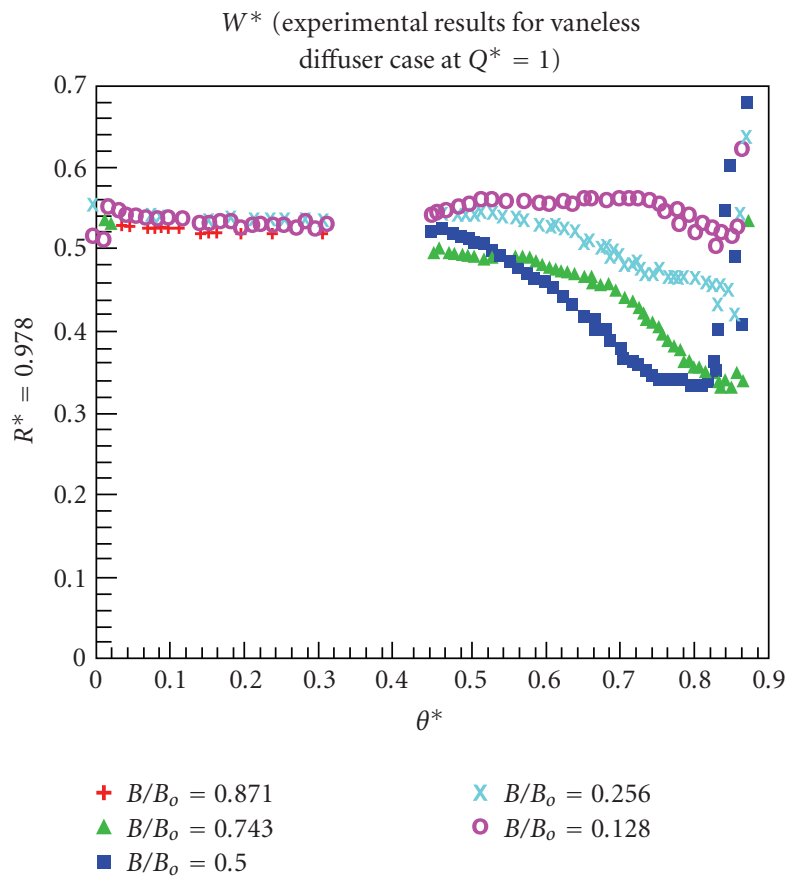

(c)

FIGURE 14: Blade to blade relative velocity evolution for vaneless diffuser.

side shroud corner as can be seen later in Figure 14. The presence of diffuser vanes in front of the impeller tends to restructure the flow in the spanwise direction at the outlet of the impeller to make it more symmetrical in this case and for this flow rate.

4.8. Blade-to-Blade Distribution of Relative Velocity at Impeller Outlet and Comparison with Vaneless Diffuser Case. Figure 13 shows the blade-to-blade plots of the normalized relative velocity for three heights and for passage 3. $\theta$ equal to 0 is located at the impeller blade trailing edge pressure side of the passage. All velocity profiles show similar trend with close values and confirm the symmetry observed around the midheight circumferential line. Relative velocity is slightly lower close to the shroud side than the hub one. Experimental data are also plotted in the figure and show the same trends as discussed earlier.

From the experimental tests with the vaneless diffuser and for exactly the impeller design flow rate $\left(Q^{*}=1\right)$, are plotted in Figure 14 the blade-to-blade distributions 
of the normalized relative velocity at five heights between hub to shroud and at three radial locations inside the impeller passage [12]. The discontinuity in velocity profile comes from data reduction procedure as explained earlier in experimental procedure.

The overall evolution of gradients for the relative velocity in Figure 13 appears to be comparable with what is observed for the vaneless diffuser case in Figure 14, at the exception of the low relative velocity zone observed at the suction side shroud corner and other points discussed in the following.

At $R_{1}^{*}$, all velocity profiles show similar gradient with close values. This relative flow gradient is in accordance with the potential theory. This is the general trend observed with vaneless diffuser case except for close to suction side shroud corner.

At $R_{2}^{*}$, the velocity profiles show similar trend as for $R_{1}^{*}$, but with the presence of a lower velocity region at midpassage. It deviates from the potential flow theory. The slope is the same as for vaneless diffuser case, but no presence of minima is observed other than close to suction side shroud corner.

At $R_{3}^{*}$, the same observations are found as for $R_{2}^{*}$, but with much greater influence of diffuser vanes. All velocity profiles show maxima at mid passage and minima close to suction side. This is a departure from the vaneless diffuser case, in which the low velocity region has extended up to mid passage but is confined to suction side shroud corner.

The jet-wake flow structure observed in the impeller outlet plane with vaneless diffuser case, as shown by Wuibaut et al. [14], is extremely restructured by the presence of diffuser vanes. This particular point needs further investigations with other flow rates, other hub-to-shroud sections with PIV measurements, other blade positions, and unsteady calculations.

\section{Conclusion}

A full $360^{\circ}$ pump impeller and diffuser flow numerical simulation in frozen rotor mode has been presented. It focuses on the flow analysis at the outlet part of the impeller facing a vaned diffuser. From analyzing such results, it appears clearly that the flow in one impeller blade passage is not exactly the same in neighboring passages; that is why taking into account the whole geometry of both impeller and diffuser in the simulation is fully justified to take into account the strong interaction effect. The results clearly demonstrate the unsteady character of the flow due to this rotor-stator interaction. These noticeable effects produce fluctuations in velocities, pressure, torque, and flow rate. They are sources of flow unsteadiness, vibration, and noise. The numerical calculations and experimental data fit rather well. It also shows a departure from the vaneless diffuser case. Frozen rotor approximation can provide part of complete real results inside the impeller passage. Further comparisons have to be made, taking into account several other blade positions, including hub-to-shroud evolutions, comparisons with already PIV measurements, and, finally, true nonstationary calculations.

\section{Nomenclature}

$\begin{array}{ll}B: & \text { Height from impeller hub }[\mathrm{m}] \\ B_{0}: & \text { Outlet impeller height }[\mathrm{m}] \\ B^{*}: & \text { Normalized height }\left(B / B_{0}\right) \\ C^{*}: & \text { Normalized absolute velocity }\left(C / U_{0}\right) \\ C_{a}^{*}: & \text { Normalized absolute axial velocity } \\ C_{r}^{*}: & \text { Normalized absolute radial velocity } \\ C_{u}^{*}: & \text { Normalized absolute tangential velocity } \\ Q^{*} & \text { Flow rate }\left[\mathrm{m}^{3} / \mathrm{s}\right] \\ Q_{n}: & \text { Design flow rate }\left[\mathrm{m}^{3} / \mathrm{s}\right] \\ Q^{*}: & \text { Normalized flow rate }\left(Q / Q_{n}\right) \\ R: & \text { Radius }[\mathrm{m}] \\ R_{0}: & \text { Outlet radius of the impeller } \\ R^{*}: & \text { Normalized radius }\left(R / R_{o}\right) \\ R_{1}^{*}, R_{2}^{*}, R_{3}^{*}: & \text { Selected normalized radii } \\ U_{0}: & \text { Impeller outlet circumferential velocity } \\ & \text { [m/s] } \\ W^{*}: & \text { Normalized relative velocity }\left(W / U_{o}\right) .\end{array}$

Greek

$\theta$ : Circumferential location $\left[^{\circ}\right]$

$\varphi$ : Main blade angular location $\left[^{\circ}\right]$.

\section{Abbreviation}

PS: Pressure side

SS: Suction side.

\section{Acknowledgment}

Special thanks are due to Patrick DUPONT from EC Lille for discussing experimental issues.

\section{References}

[1] H. Krain, "Study on centrifugal impeller and diffuser flow," Journal of Engineering for Power, vol. 103, no. 4, pp. 688-697, 1981.

[2] M. Sinha and J. Katz, "Quantitative visualization of the flow in a centrifugal pump with diffuser vanes-I: nn flow structures and turbulence," Journal of Fluids Engineering, vol. 122, no. 1, pp. 97-107, 2000.

[3] J. Feng, F. K. Benra, and H. J. Dohmen, "A Study on ImpellerDiffuser Interactions in a Radial Pump," in Proceedings of the 7th European Conference on Turbomachinery, Fluid Dynamics and Thermodynamics, pp. 773-782, Athens, Greece, 2007.

[4] J. P. Johnston and R. C. Dean, "Losses in vaneless diffusers of centrifugal compressors and pumps," Journal of Engineering for Power, vol. 88, pp. 49-62, 1966.

[5] W. N. Dawes, "Simulation of the unsteady interaction of a centrifugal impeller with its vaned diffuser: flow analysis," Journal of Turbomachinery, vol. 117, no. 2, pp. 213-222, 1995.

[6] N. Arndt, A. J. Acosta, C. E. Brennen, and T. K. Caughey, "Experimental investigation of rotor-stator interaction in a 
centrifugal pump with several vaned diffusers," Journal of Turbomachinery, vol. 112, no. 1, pp. 98-108, 1990.

[7] K. Eisele, Z. Zhang, M. V. Casey, J. Gülich, and A. Schachenmann, "Flow analysis in a pump diffuser-part 1: LDA and PTV measurements of the unsteady flow," Journal of Fluids Engineering, vol. 119, no. 4, pp. 968-977, 1997.

[8] G. Pavesi, G. Cavazzini, P. Dupont, S. Coudert, G. Caignaert, and G. Bois, "Analysis of rotor-stator interactions effects within the vaned diffuser of a radial flow pump," in Proceedings of the 23rd IAHR Symposium on Hydraulic Machinery and Systems, Yokohama, Japan, 2006.

[9] T. Meakhail and S. O. Park, "A study of impeller-diffuservolute interaction in centrifugal fan," Journal of Turbomachinery, vol. 127, no. 1, pp. 84-90, 2005.

[10] K. Majidi, "Numerical study of unsteady flow in a centrifugal pump," Journal of Turbomachinery, vol. 127, no. 2, pp. 363371, 2005.

[11] G. Wuibaut, G. Bois, M. El Hajem, A. Akhras, and J. Champagne, "Optical PIV and LDV comparisons of internal flow investigations in SHF impeller," International Journal of Rotating Machinery, vol. 2006, Article ID 69521, 9 pages, 2006.

[12] G. Wuibaut, G. Bois, P. Dupont, G. Caignaert, and M. Stanislas, "PIV measurements in the impeller and the vaneless diffuser of a radial flow pump in design and off-design operating conditions," in Proceedings of the ASME Fluids Engineering Division, New Orleans, La, USA, 2001.

[13] G. Wuibaut, P. Dupont, G. Caignaert, and G. Bois, "Rotor stator interactions in a vaned diffuser radial flow pump," in Proceedings of the 22nd IAHR Symposium on Hydraulic Machinery and Systems, Stockholm, Sweden, 2004.

[14] G. Wuibaut, G. Bois, G. Caignaert, P. Dupont, and M. Stanislas, "Experimental analysis of interactions between the impeller and the vaned diffuser of a radial flow pump," in Proceedings of the 21st IAHR Symposium on Hydraulic Machinery and Systems, Lausanne, Switzerland, 2002. 

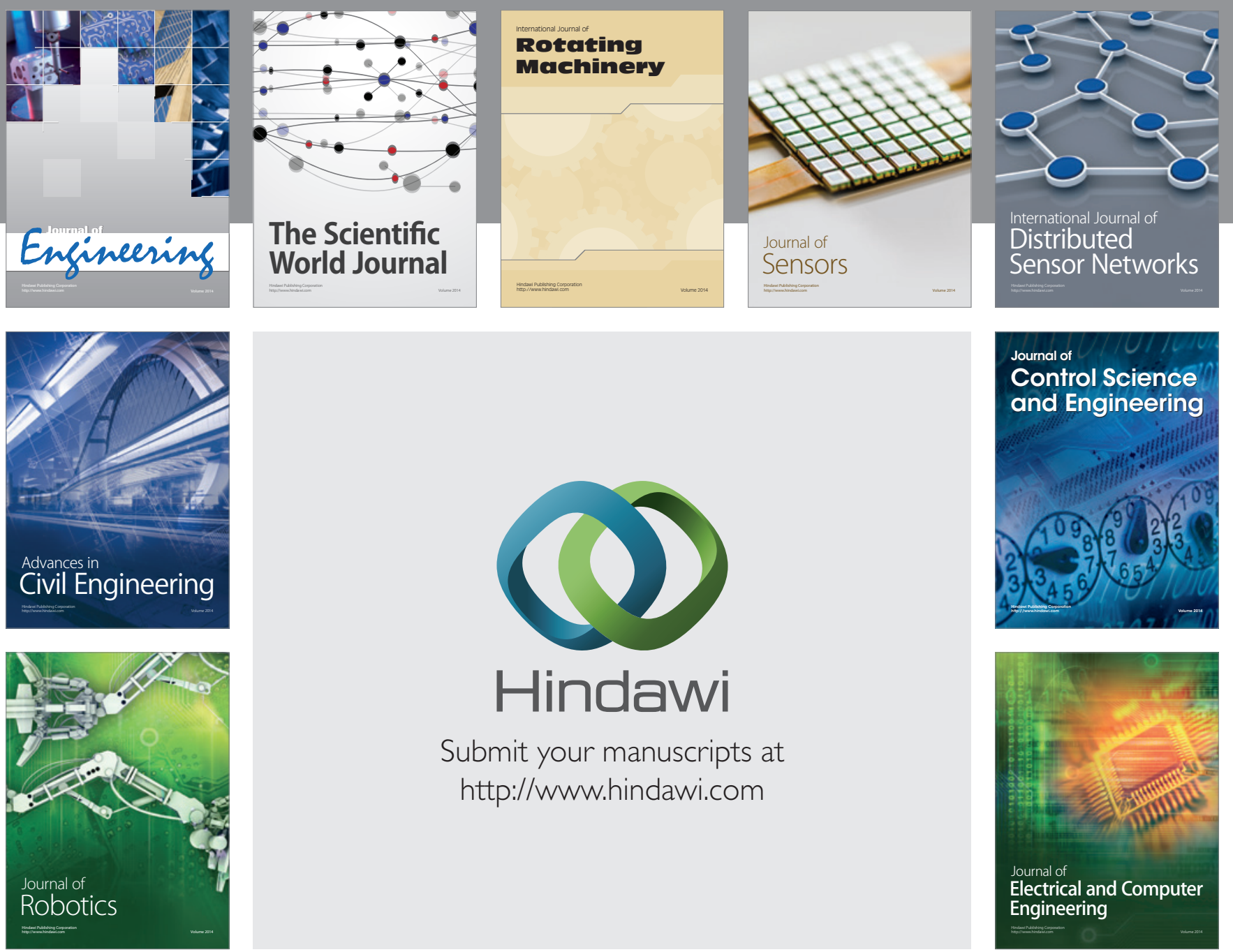

Submit your manuscripts at

http://www.hindawi.com
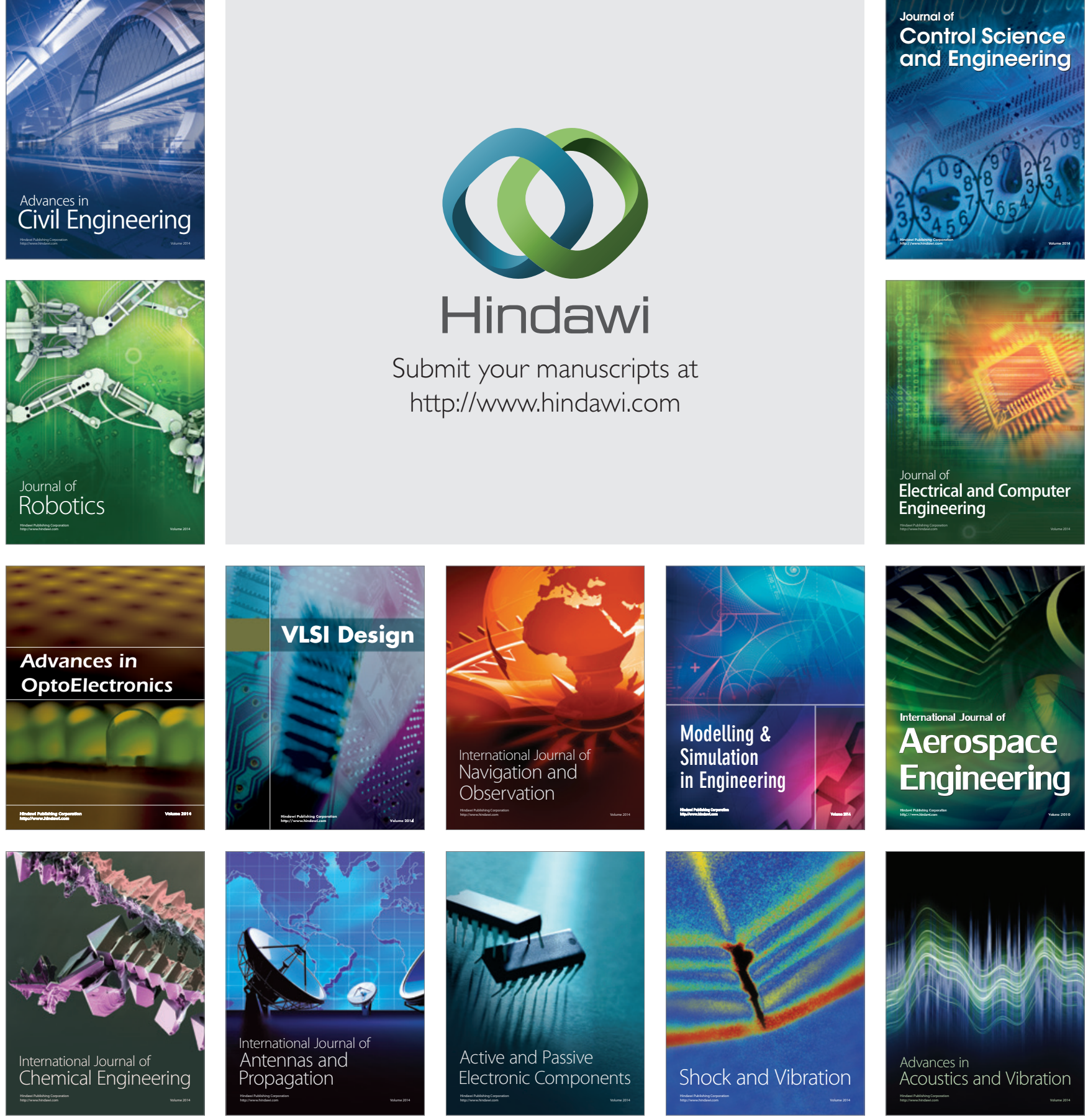